\title{
Administração estratégica e indústria criativa: uma discussão sobre recursos e capacidades em grupos musicais
}

\author{
Strategic management and creative industry: a \\ discussion on resources and capabilities in music \\ groups
}

\author{
Afonso Carneiro Lima ${ }^{1}$ \\ José Augusto Giesbrecht da Silveira² \\ Fátima Regina Ney Matos ${ }^{3}$ \\ André Moura Xavier ${ }^{4}$
}

\section{Resumo}

A indústria criativa vem crescendo continuamente em diversos países e a produção musical responde por grande parte desse crescimento. Considerando tal fenômeno, este ensaio versa sobre a produção musical, especificamente o rock, a partir da Visão Baseada nos Recursos da Firma (VBR), utilizando-se da analogia como método de argumentação e estabelecendo como parâmetros comparativos os ativos tangíveis, ativos intangíveis e capacidades - conceitos da VBR. Mudanças no cenário cultural promovidas por inovações tecnológicas e pela internet têm aberto novas possibilidades para artistas-empreendedores; como resultado, há uma clara necessidade de esses atores repensarem sua realidade e seus objetivos nesse

Mestre e doutor em Administração pela Faculdade de Economia, Administração e Contabilidade da Universidade de São Paulo (FEA-USP). Professor da Universidade de Fortaleza (UNIFOR). E-mail: afonsolima@unifor.br

2 Mestre e doutor em Administração pela Escola de Administração de Empresas de São Paulo da Fundação Getúlio Vargas (EAESP-FGV). Professor da Faculdade de Economia, Administração e Contabilidade da Universidade de São Paulo (FEA-USP). E-mail: jags@usp.br

3 Mestre em Administração pela Universidade Estadual do Ceará e doutora em Administração pela Universidade Federal de Pernambuco. Professora da Universidade de Fortaleza (UNIFOR). E-mail: fneymatos@unifor.br

4 Consultor em Responsabilidade Social Corporativa, PhD em Administração pelo Departamento de Engenharia de Minas da Universidade da Columbia Britânica pela pesquisador no Instituto de Indústrias Extrativas da Universidade da Columbia Britânica, Canadá. E-mail: andre.xavier@ ubc.ca 
contexto. Este ensaio argumenta que a ideia da banda como uma organização que opta por um conjunto de recursos e desenvolve capacidades para atingir objetivos estratégicos certamente contribui para essa tarefa.

Palavras-chave: Indústria Criativa. Administração Estratégica. Visão Baseada nos Recursos da Firma. Competências. Capacidades.

\section{Abstract}

Thecreative industryhas been growing continuallyin many countriesand musical productionaccounts formuch of this growth. Considering this phenomenon, this essay approaches musical production, specificallyrock music,through the Resource-Based Viewof the Firm (RBV) by means of analogiesas an argumentation resource and,setting ascomparative parameters, the tangible andintangible assets andcapabilities, concepts of the RBV.Changes in thecultural scenariopromotedby technological innovationand the internet haveopened new possibilities for artistentrepreneurs;as a result there isa clear need for them torethinktheir reality and purpose. This essay argues that the idea ofa bandas an organization thatchooses foraset of resources and develops capabilities toachieve strategic goalscertainly contributes tothis task.

Keywords: Cultural Industry. Strategic Management. Resource-Based View. Competencies. Capabilities.

\section{Introdução}

Originado principalmente a partir do rhytm and blues (R\&B) e da música country norte-americana, o rock ${ }^{5}$ surgiu como um estilo musical nos Estados Unidos em meados da década de 1950, tornandose uma forma dominante de música popular em diversos países nas décadas posteriores (PETERSON, 1990; HEADLAM, 1997). A ascensão desse gênero pode ser entendida como um momento cultural em que características musicais afro-americanas penetraram e revitalizaram a música popular branca, graças, em grande parte, a tecnologias de gravação e reprodução de som.

5 Assim como em Peterson (1990), o termo rock será utilizado neste trabalho para se referir a todas as formas da música, até as formas desse estilo na década de 1950, geralmente designadas como "rock 'n' roll" e "rockabilly". 
No início do século XXI, o acesso mais amplo a essas tecnologias, a ascensão de novas mídias de massa, a ubiquidade dos computadores pessoais e a dinamização da internet promoveram grandes mudanças no que se refere à produção, distribuição e consumo da música popular, impactando na indústria fonográfica e em artistas e diversos outros grupos ligados à indústria da cultura (NAKANO, 2010).

A partir de uma reflexão acerca de como grupos de rock podem repensar seu papelem meio a um novo contexto industrial e mercadológico, este ensaio propõe uma perspectiva focada na comparação entre os diferentes recursos presentes na organização empresarial e aqueles evidenciados em bandas de rock, na medida em que estes podem ser compreendidos e empregados visando o aproveitamento de novas oportunidades em um novo contexto ambiental.

A analogia pode ser considerada um método para a construção de uma argumentação, sendo ainda uma poderosa ferramenta para a análise social (MANNING, 1979; PERELMAN; OLBRECHTS-TYTECA, 1996; TINKER, 1986). O seu emprego como recurso metodológico se faz apropriado na medida em que se deseja estruturar um encadeamento lógico-argumentativo valendo-se da comparação entre dois conceitos distintos, objetivando-se a formação de outros conceitos (MORGAN, 1996; VERGARA, 2005). Vergara e Carpilovsky (1998) complementam que a validade da metáfora enquanto método de pesquisa advém da possibilidade de se enxergar os fenômenos sociais sob um ponto de vista distinto, gerando insights para compreendê-los e atuar sobre eles de uma maneira inovadora. Entretanto, a parcialidade desse método, uma vez que considera a variável de comparação isoladamente, "pode comprometer o entendimento das diversas influências que atuam sobre o fenômeno, como discrepâncias fundamentais" (VERGARA, 2005, p. 39). A VBR foi escolhida como marco teórico por privilegiar os elementos internos à organização que influenciam o seu crescimento e a sua evolução, tanto recursos quanto decisões gerenciais, frente ao seu ambiente (ADNER; HELFAT, 2003; HANSEN; WERNERFELT, 1989; PENROSE, 1959). 
O foco do trabalho se justifica pelo fato de ser a produção musical um importante elemento na chamada indústria criativa: a produção musical, ao incorporar atividades intensivas em conhecimento, potencializa comercialmente a criatividade, influenciando positivamente ainda outras atividades econômicas (BENDASSOLI et al., 2009; CAVES, 2000; NAKANO, 2010). Assim, procurou-se atender ao apelo de Nowotny et al. (2001) a respeito da relação rigor-relevância na pesquisa científica. A escolha do gênero rock, por sua vez, justifica-se por ser uma forma ou estilo dominante de música popular em diversos países (FRITH, 1981a; LULL, 1992), tendo sido o alicerce de algumas das grandes empresas da indústria fonográfica a partir da segunda metade do século XX (WICKE; DEVESON, 1982).

Neste texto em particular, cabe destacar uma limitação: a questão relacionada à vantagem competitiva sustentável, apresentada na esfera das organizações empresariais como a lucratividade superior à concorrência (HAX; MAJLUF, 1996; DAY et al., 1997, p. 59-60; MONTGOMERY; PORTER, 1998), aplica-se de maneira parcial no contexto das bandas de rock, mesmo porque, segundo Arend (2003), "desempenho superior" possui diversas definições e medidas (e.g., contábeis, financeiras e mercadológicas). Mesmo assim, a compreensão e a escolha pelos diversos tipos de recursos que dão suporte a essa vantagem e o desenvolvimento de capacidades, de acordo com a VBR, pode ser expandido ao contexto das bandas de rock, presenteando-lhes com uma perspectiva relevante sobre a sua dinâmica: uma organização estrategicamente orientada.

Este ensaio está dividido da seguinte forma: a primeira seção trata do rock como fenômeno da modernidade e a relação que os grupos guardam com organizações empresariais a partir da compreensão do papel de seus recursos estratégicos; a segunda seção discute analogias entre recursos tangíveis, intangíveis e capacidades entre organizações empresariais e bandas de rock; e a terceira e última seção apresenta as conclusões dessa reflexão. 


\section{0 rock como fenômeno da modernidade}

As organizações modernas são fruto da Revolução Industrial e seus produtos ou serviços pressupõem o racionalismo fundamentado na especialização técnica e na eficiência. Dois exemplos de organizações modernas são as empresas modernas e os grupos musicais, desde orquestras a grupos de rock.

Considerando os efeitos da Revolução Industrial, Toffler (1990) cita a incorporação de princípios fabris aos diversos setores e atividades sociais, inclusive nas artes, em que o patrono, aos poucos, cedia às forças de mercado e artistas, escritores e músicos, convertiam-se cada vez mais em produtos para consumidores anônimos.

Nesse cenário de mudanças sociais, surgiam as salas de concerto em diversas capitais europeias, as orquestras sinfônicas (uma transformação da música de câmara), sua estrutura hierárquica e os financiadores da produção musical (TOFFLER, 1990). A moderna orquestra sinfônica, instituição industrial para a qual Beethoven, Mendelssohn, Schubert, e Brahms escreviam suas sinfonias, vendia seu produto para um mercado de massa - eventualmente adicionando registros fonográficos a sua produção. Nascia, assim, a indústria da música a partir da arte e de sua capitalização. (WICKE; DEVESON, 1982; TOFFLER, 1990).

Frith (1981a) descreve o rock como uma commodity produzida e consumida em massa. Considerando-se sua ascensão como símbolo cultural, podem-lhe ser atribuídas três forças potencializadoras: o surgimento de personalidades que se utilizaram da criatividade em suas apresentações, mudanças na composição de audiências, particularmente o grande número de pessoas jovens nascidas após a Segunda Guerra Mundial (baby-boomers) e a transformação da indústria cultural comercial, entendida como o conjunto elaborado de elementos que incluem a indústria da música (e empresas não relacionadas) e a transmissão (broadcasting) de rádio e de televisão (FRITH, 1992; GROSSBERG, 1984; PETERSON, 1990; WICKE; DEVESON, 1982). 
Embora não se possa definir exatamente o rock enquanto gênero musical, já que o termo possui diferentes conotações (FORNÄS, 1995; WICKE; DEVESON, 1982), pode-se caracterizá-lo por suas fortes texturas, pelo alto volume com que geralmente é reproduzido ou tocado e, geralmente, pelas letras sugestivas ou de rebeldia. Sua audiência primária é a juventude; assim, músicas que descrevem conflitos filosóficos do ponto de vista da juventude são comuns no rock (LULL, 1992). Bowie (2011), no entanto, propõe um conjunto de elementos que, agregados, ajudam a definir o estilo e a fazer com que a música seja extraordinariamente valorizada pelas suas audiências: tecnologia, poesia, o conceito de liberação, utilização de arquivos fonográficos como inputs ao processo criativo, a concepção de gravações como trabalhos de arte, novas formas de colaboração, amplificação eletrônica, uma forte batida, e perfil artístico. É verdade que poucos desses elementos são inteiramente únicos ao rock, no entanto, foram mais impactantes no rock do que em outras formas musicais (BOWIE, 2011).

Para Frith (1981b), há um importante argumento por trás do rock (derivado da música folk) que trata não de como a música é construída, mas sim, de como ela funciona: o rock é uma forma de expressar (ou refletir) um modo de vida; tal estilo enquanto produto é utilizado por seus ouvintes como música folk: articula valores comunais e trata de problemas sociais compartilhados. Em outras palavras, o cerne do rock está nas subculturas ao invés do simples ato de "fazer música"; a questão de como a música vem a representar seus ouvintes é um ponto muito relevante.

De acordo com Hamm (1981), o rock é menos orientado para a linguagem do que outros estilos que o procederam; a objetividade das mensagens de suas letras e seus próprios títulos são, assim, a essência. Além disso, o rock incita movimento físico vigoroso; promove uma dança social, em que o indivíduo se torna parte de uma celebração. Ainda segundo Hamm (1981), essas características corroboraram para a aceitação do rock em outros países, gerando ainda diversas ramificações: rock ' $n$ ' roll, classical rock, punk rock, heavy metal etc.cada uma delas destinadas a representar subculturas em todo o mundo. 


\section{0 rock e a Visão Baseada nos Recursos da Firma}

Se para Fornäs (1995) a confecção da música necessariamente envolve o trabalho cooperativo de pessoas em certos cenários institucionais e com subjetividades específicas, pode-se inferir que a banda de rock, sob uma análise mais específica, lida com questões semelhantes àquelas presentes no âmbito das organizações empresariais. Uma dessas questões seria a busca e a exploração de recursos e capacidades que permitam desempenho superior, um dos principais focos da VBR.

A VBR é uma abordagem da Administração Estratégica cuja ênfase está na construção da vantagem competitiva através da captura de rendas empreendedoras oriundas de vantagens de eficiência essenciais no nível da empresa; assim, a vantagem competitiva, de acordo com a VBR, estaria menos relacionada ao posicionamento da empresa em sua indústria a partir de suas escolhas de atuação em linhas de produtomercado; estaria mais relacionada àqueles recursos idiossincráticos e difíceis de serem imitados, os quais permitem a empresa praticar preços menores ou oferecer qualidade superior e desempenho de produto (GAVETTI; LEVINTHAL, 2004; PENROSE, 1959; TEECE et al., 1997).

Isoladamente, esses recursos não se sustentam; porém, a partir de um conjunto único de recursos composto tanto de ativos quanto de elementos individuais, sociais e organizacionais, estabelecem-se alicerces para a geração de vantagem competitiva sustentável(FAHY, 2000; FAHY; SMITHEE, 1999; HITT et al., 2003). Barney (1991), nesse sentido, instituía a premissa de que os recursos geradores de vantagem competitiva devem atender quatro condições básicas: possuírem valor, serem raros ou escassos, serem difíceis de imitar e serem difíceis de substituir.

Uma importante consideração acerca de vantagens competitivas para o universo das bandas de rock são as rápidas e intensas mudanças na indústria cultural. No âmbito da firma, tais vantagens refletem mais um direcionamento estratégico da organização do que objetivos pontuais a serem atingidos (CHAHARBAGHI; LYNCH, 1999). Assim, a existência da 
firma está intrinsecamente associada à sua capacidade de compreender as mudanças ambientais e adaptar-se a elas, assim como optar pelo domínio de recursos os quais, num contexto dinâmico, não são perenes, mas inconstantes. Para bandas de rock, compreender o valor que um conjunto de recursos pode lhes trazer é fundamental para que possam manter-se flexíveis e atuantes em contextos dinâmicos e complexos. Os diferentes recursos à sua disposição podem ser classificados de acordo com a própria VBR, o que pode Ihes auxiliar nesse entendimento.

Há uma pluralidade de classificações quanto aos recursos organizacionais na literatura. Nieto e Perez (2002), por exemplo, consideram ativos de inventário, de habilidades e de capacidades; Miller e Shamsie (1996), por sua vez, classificam os recursos em baseados em propriedade e em conhecimento. Essas e outras classificações relativas aos recursos da empresa, de uma maneira geral, podem ser resumidas em três categorias gerais: ativos tangíveis, intangíveis e capacidades (BARNEY; HESTERLY, 2007, p. 64; HITT et al., 2003; PEREIRA; FORTE, 2008). Assim, optou-se por esta última classificação como estrutura de comparação, a qual será tratada a seguir.

\section{Recursos tangíveis}

Ativos classificados como tangíveis são ativos físicos ou ativos baseados em propriedade que se caracterizam por serem visíveis e passíveis de contabilização. Nas empresas,esses ativos são divididos tipicamente em recursos financeiros (i.e.,capacidade de tomar empréstimos, habilidade de gerar fundos internamente); recursos organizacionais (i.e., estrutura formal e sistemas de coordenação e controle); recursos físicos (i.e., sofisticação de equipamentos e localização de instalações); e recursos tecnológicos (i.e., estoque de tecnologias, patentes e marcas registradas) (HITT et al., 2003). Todos esses ativos podem ter seus respectivos valores expressos em demonstrativos financeiros.

Em grupos de rock, recursos tangíveis compreenderiam a ampla variedade de instrumentos musicais e equipamentos utilizados tanto para a gravação, quanto para a reprodução da música (apresentações), 
além de recursos de som e imagem: guitarras elétricas fortemente amplificadas (incluindo baixo, rhythm e lead) e bateria que sejam capazes de reproduzir melodias, harmonias e ritmos fortes orientados à dança ou a experiências emocionais. Alguns desses ativos são tão valiosos que são quase indissociáveis da própria imagem de algumas bandas, i.e. guitarras de personalidades como David Gilmour, Jimmy Page e Slash, o visual e a pluralidade da percussão de Terry Bozzio, e a estrutura de espetáculos como o da banda Kiss. Todos esses ativos tangíveis, assim como outros hardwares moldam o som na medida em que são empregados na reprodução da música e de seus aspectos estéticos, tais como distorções, fuzz-tones, wah-wahse diversas outras técnicas (BOWIE, 2011; FORNÄS, 1995; LONGFELLOW, 2003).

Quanto à produção musical a partir de novas tecnologias, Lull (1992) ressalta que para músicos ou bandas se tornarem populares e ocuparem posições de significativa influência, as texturas de áudio criadas por eles devem passar por considerável industrialização. Desenvolvimentos na tecnologia musical (antes restritos às grandes empresas gravadoras e agora cada vez mais disponíveis ao alcance de diversos profissionais da música) como computadores, multitrack tape recorders, sintetizadores, sequencers, sampling e MIDI, não só alteraram a qualidade do produto final,mas também o significado dos instrumentos musicais, permitindo a elaboração de diferentes estilos de música popular (FORNÄS, 1995; JULIEN, 1999; LONGFELOW, 2003).A opção pela exploração mais intensa de tais ativos permitiu à banda FooFighters acelerar o processo de produção musical e criar sinergias entre seus membros (MOLL, 2011). Quanto à inovação a partir dessas tecnologias, Clarke (1983), cita a música de Jimmy Hendrix para ilustrar a habilidade do músico em capturar e controlar sons;novas tecnologias se tornaram meios de ampliar formas e tradições musicais, estabelecendo novas possibilidades para elas ${ }^{6}$.

6 As tecnologias que permitem a experimentação com sons se enquadram como ativos tangíveis. As habilidades em manipulá-los podem ser descritos como recursos intangíveis, já que se referem a habilidades intelectuais específicas, difíceis de mensurar e imitar. 
Para Hamm (1981), poucas bandas dos anos de 1960 e 1970 foram capazes de resistir à tentação de criar discos com arranjos mais intensos e elaborados enquanto suas carreiras progrediam e prosperavam. Hamm (1981) cita o caso dos Beatles. No início de sua trajetória, os quatro músicos produziam um som claro, vibrante e limpo tanto em suas apresentações quanto em seus primeiros discos. Gradualmente, passaram a tocar com uma variedade maior de instrumentos, introduzindo outros músicos na confecção de sons mais variados. O produtor da banda, George Martin, aos poucos perdia o controle artístico sobre ela e as experimentações e arranjos e as técnicas de estúdio permitiram a elaboração de sons impossíveis de serem reproduzidos em apresentações ao vivo. Para Bowie (2011), esse fenômeno teve importante contribuição para o desenvolvimento do rock enquanto estilo.

Mas, se por um lado o desenvolvimento da moderna tecnologia musical, especialmente a guitarra elétrica e o baixo, deu vida ao rock, atribuindo volume e agressividade à musica popular norte-americana nas décadas de 1950 e 1960, por outro, a ulterior evolução da tecnologia musical, tirou parte dessa característica. O som de salas de concerto tecnologicamente sofisticadas de bandas como Genesis, Rush, Journey, Jethro Tull e Yes na década de 1970 distanciaram os músicos dos fãs, enfatizando virtuosidade musical e experimentações técnicas em detrimento da emoção em seu estado mais puro. Nesse contexto, o surgimento de outros estilos como o punk rock e o heavy metal, foi em parte uma reação aos estilos impessoais e pretensiosos criados pelas bandas de "art rock" da década de 1970 na medida em que refletiam um retorno ao espírito original do rock (LULL, 1992).

Tanto a busca pelas emoções mais cruas e primitivas, de um lado, quanto a virtuosidade e o espetáculo de imagens e sons, de outro, requerem o estabelecimento de objetivos estratégicos por parte das bandas: uma banda de rock necessita de coerência tendo em vista a sua essência em representar ideias, sentimentos e emoções, assim, a importância da escolha pelos ativos tangíveis: a qualidade, quantidade e combinação de diferentes instrumentos, a qualidade e quantidade de hardwares (amplificadores, caixas de som, dimensão de palco etc.), 
podem dar suporte ou não, assim como nas empresas, ao seu objetivo de comunicação, ou missão, a razão de existência da própria banda. Nessa linha, cita-se o movimento New Wave britânico, cujas bandas eram caracterizadas por sua preferência pelo uso de sintetizadores analógicos e digitais, ao invés de guitarras elétricas, como elemento marcante de seu som.

\section{Recursos intangíveis}

Recursos intangíveis são caracterizados principalmente por sua difícil mensuração ou imitação e estão tipicamente enraizados na história de uma organização, acumulando-se ao longo do tempo. De acordo com Hitt et al. (2003) e Hall (1992), alguns dos principais recursos intangíveis na esfera das empresas são: recursos humanos (i.e. conhecimento, confiança, rotinas organizacionais); recursos de inovação (i.e. ideias, capacidade de inovação); e recursos associados à reputação (i.e. reputação com clientes e fornecedores, percepções quanto à qualidade, durabilidade e confiabilidade), todos eles complexos e específicos.

Lull (1992) justifica que artistas ou bandas que queiram se tornar populares devem obter contratos de gravação na indústria fonográfica além de considerável exposição em mídias. A indústria da música, a partir da produção musical e suas tecnologias, assim como a mídia eletrônica, estão intimamente envolvidas nesse processo; ativos tangíveis, representados pela tecnologia de produção e instrumentação, devem estar alinhados a ativos intangíveis como capacidades gerenciais (por meio de contratos), bem como a relacionamentos singulares com pessoas ou organizações que permitam sua exposição através de diferentes canais.

Ativos intangíveis como geradores de vantagem competitiva sustentável podem ainda abranger a maneira como o artista ou músico se comunica: o know-how em despertar emoções em sua audiência, assim como suas habilidades interpretativas, o que contribui para as percepções positivas da audiência. Esses exemplos se enquadram no que Fornäs (1995) descreve como competência musical (musical 
competence) as quais podem requerer habilidades complexas e específicas que, por sua vez, são indissociáveis aos dois componentes presentes no argumento rock-folk, a música como uma forma autêntica de reflexão sobre uma experiência e, ao mesmo tempo, como uma forma de reflexo da experiência de uma comunidade (FRITH, 1981b). Esses dois argumentos podem ser exemplificados pela imagem excêntrica da banda The Darkness e sua paródia ao rock da década de 1970.

Ainda nessa perspectiva, Lull (1992) cita a importância da repetição clara e temática na música popular a partir de certos componentes melódicos (riffs e refrões) que captam a atenção do público. A composição ou a apresentação da música seja ao vivo ou gravada é uma atividade comunicativa altamente valorizada em todas as sociedades. Músicos populares (e estrelas do rock) são admirados ou mesmo adorados não somente por suas habilidades em falar a suas audiências, mas pelas suas habilidades em escrever música e tocá-las ou apresentá-las publicamente. Um artista cujo único contato com a audiência é através da venda de milhões de CDs se comunica pessoalmente com cada um de seus ouvintes. "[...] qualquer que seja seu som ou significado, a música se origina e reside nos mundos social e cultural das pessoas" (LULL, 1992, p. 2).

As audiências, por sua vez, ao buscarem a música como formas de estímulos emocionais e intelectuais, participam da música popular de maneira física, emocional e cognitiva (LULL, 1992, p. 19; TEKMAN; HORTAÇSU, 2002b). O ouvinte pode relacionar-se à música diretamente, experimentando-a de maneira bastante pessoal. Essa comunicação ocorre entre o músico e o indivíduo, geralmente mediado pela tecnologia, embora as dimensões sociais desse processo sejam muito mais amplas (LULL, 1992).

Assim, pode-se afirmar que a habilidade comunicativa está de acordo com aquilo que se quer transmitir, i.e. rebeldia, lascívia, visão política, ou qualquer outra forma de libertação (FORNÄS, 1995); a mensagem a partir das letras e a unicidade de como elas são transmitidas pelos artistas ou músicos, assim, se enquadraria como uma habilidade 
específica, ou mesmo intelectual, isto é, uma forma de ativo intangível. Entretanto, deve-se atentar para uma consideração de Frith (1981a; 1981b): em suas origens, o rock era uma forma de música popular que não era "imposta de cima", que não falseava emoções. O chamado rock community se refere não a uma instituição ou a um conjunto de pessoas, mas a uma sensação. Essa fundamental característica reflete a "base artística", um dos elementos de Bowie (2011) que abrange: propósito artístico, individualidade, integridade, inovação e atemporalidade. Embora esse argumento se refira ao rock na década de 1960, essa mesma base artística continua válida nos dias atuais, assemelhando-se aos elementos caracterizadores dos recursos intangíveis.

A reputação, assim como nas empresas, enquadra-se como um ativo intangível para bandas de rock. A reputação junto a audiências e a outros públicos consistiria primordialmente na opção da banda em manter-se fiel a uma proposta de comunicação. Nesse aspecto, há dois extremos que se estendem aos grupos de rock: o acompanhamento contínuo de tendências tecnológicas ou de estéticas e a manutenção de um estilo próprio ou de uma estética que pouco evolui em seus aspectos básicos, mas que pode sofrer inovações incrementais. A reputação de uma banda em relação a sua proposta de comunicação pode transcender gerações e, geralmente, o público se mantém fiel à banda enquanto perceber que ela se encaixa dentro de uma proposta, i.e. virtuosidade, valores etc.

Os ativos intangíveis, assim como nas empresas, vêm sendo cada vez mais importantes para as bandas de rock. Rendas derivadas de ativos tangíveis como direitos autorais, royalties e merchandising têm se reduzido substancialmente com o desenvolvimento da tecnologia digital, a internet e os computadores pessoais (GIBSON, 2008). Assim, evidencia-se cada vez mais o foco das bandas em explorar rendas a partir de recursos intangíveis: novas ideias de apresentações, i.e., eventos temáticos e interações com grupos diversos como os próprios fãs e patrocinadores. Tais esforços se centralizam na capacidade da banda em gerar emoções cada vez mais memoráveis, únicas para seus fãs em apresentações mais frequentes e envolventes. 
Quanto aos relacionamentos, se por um lado a internet gerou profundas mudanças na estrutura da indústria fonográfica, por outro, ela permitiu que usuários (artistas e músicos) encontrassem seu espaço de atuação direta na indústria cultural, possibilitando-os ainda a engajar fãs e outros grupos relevantes, além de monitorá-los através sistemas de informações ou mesmo através de redes sociais. A internet ainda lhes possibilita administrar funções diversas: painéis de pesquisa, produção e distribuição etc.

\section{Capacidades}

Recursos baseados em capacidades se manifestam através de interações complexas entre ativos tangíveis e intangíveis; as capacidades permitem a organização em pregar outros recursos sob seu controle, integrados com o propósito de atingir algum objetivo. Exemplos de capacidade são a colaboração entre diferentes áreas funcionais e a coordenação e integração de diferentes competências (BARNEY; HESTERLY, 2007; HELFAT; RAUBITSCHEK, 2000). Quando recursos e capacidades são responsáveis pela vantagem competitiva da firma, elas podem ser definidas como suas competências centrais (DAY, 1994; PRAHALAD; HAMEL, 1990). Originando-se com o tempo através de processos de aprendizado, essas competências são representadas pelas atividades que a empresa desempenha especialmente bem em comparação aos competidores, adicionando valor de maneira excepcional a seus produtos e serviços ao longo do tempo. Por serem recursos complexos, baseados na interação (em muitos casos,única), além de envolverem uma série de recursos complementares, as capacidades são os recursos mais difíceis de serem imitados e avaliados sob a ótica econômica(HITT et al., 2003).

A interação, assim como a complementaridade de competências, pode se evidenciar nas bandas de rock. As capacidades estão presentes na unicidade de parcerias criativas, por meio de virtuosidades combinadas entre diferentes músicos num projeto musical, i.e., a banda Metallica e a Orquestra Sinfônica de São Francisco, ou entre integrantes ao longo da existência de uma banda, i.e. Mick Jagger e 
Keith Richards e Simon e Garfunkel, mas também na interação entre músicos e público, i.e. Elvis Presley e a banda Kiss e seus respectivos públicos. A música é uma mistura de significados pessoais, sociais e culturais e promove experiências extraordinárias tanto para músicos e artistas quanto para ouvintes como emoções, vulnerabilidades, triunfos, celebrações e antagonismos da vida que podem ser testemunhados ou vividos individualmente ou compartilhados coletivamente (BOWIE, 2011; FRITH, 1981b; LULL, 1992; TEKMAN; HORTAÇSU, 2002a).

Um forte argumento em favor da exploração de capacidades em bandas de rock é o conservadorismo e o convencionalismo a partir da tradição da imitação que ainda prevalecem na música popular e também no rock. Artistas populares escrevem suas músicas seguindo uma estrutura de som previsível: introdução de um refrão logo no início da composição, solos instrumentais sucintos quando utilizados, assim como a eliminação de instrumentação dissonante. Além disso, há a tendência de artistas que criam músicas de sucesso em tentar copiar trabalhos anteriores; bandas tentam fechar contratos de gravação a partir da imitação de outros artistas ou grupos de sucesso, inserindo seu som dentro de um espectro de texturas que empresas gravadoras acreditam ser comercializáveis. No entanto, esse mimetismo pode não só restringir a potencialidade do grupo musical em cativar continuamente audiências, mas também privá-la de inovar através da busca por novas texturas e incorporar novos sons e estruturas musicais em sua produção, suprimindo-Ihe um estilo próprio que lhe possa atribuir unicidade, uma vez que essa prática oculta um conjunto de recursos existentes e que podem ser utilizados pelo grupo.

A capacidade que uma banda tem de desenvolver relacionamentos criativos com outros grupos musicais ou artistas pode servir como suporte à busca contínua por objetivos estratégicos, i.e. bandas que mesclam sua sonoridade pesada a diferentes ritmos ou até à leveza de uma orquestra sinfônica. Da mesma forma, a capacidade de relacionamento da banda com diversos profissionais ligados às atividades de produção pode fornecer diferentes pontos de vista acerca de determinada essência musical priorizada pela banda ao longo de sua trajetória, pontos de 
vista que por sua vez podem auxiliá-la a buscar novas texturas dentro dessa mesma essência. O papel dos ativos tangíveis (instrumentos, hardware e tecnologia) em meio às capacidades, seria fornecer subsídio à construção criativa, ao consumo, e à utilização da música, tanto pelos seus criadores quanto pelas audiências (idem).

Nesse mesmo conceito de interação de habilidades técnicas, criativas e colaborativas, as bandas de rock e sua música podem ser vistas coletivamente como elementos de um movimento. Para Durant (1985), a emergência de movimentos como Mod ou Electro Pop pode ser atribuída ao processo contínuo de rápidas mudanças de estilos musicais e, mais amplamente, da cultura popular, apontado pelo autor como um sinal de vitalidade; à lógica de produção capitalista que, ao demandar novos e diferentes produtos a serem comercializados, vêse obrigada a especular num amplo espectro de formas de novidade; ou à busca contínua entre jovens pela autodeterminação, através do desengajamento de quaisquer estilos de representação dominante (DURANT, 1985). Independentemente de seus objetivos estratégicos, a integração de recursos, a comunhão de valores individuais e os diferentes papéis desempenhados pelos integrantes de uma banda acabam por enquadrá-las em algum movimento; a ideia de pertencer a algum movimento, ou talvez cocriá-lo (i.e. Nirvana e o movimento grunge) transmitiria a essência da banda, a escolha da sua própria estética refletida na interação com sua audiência. Em outras palavras, essa ideia de classificação convidaria o grupo a refletir acerca de suas origens e essência, estabelecer quais emoções ela buscará despertar entre suas audiências e a partir de quais recursos ela fará isso.

\section{Conclusão}

A partir de um estudo comparativo, procurou-se explorar similaridades entre a organização empresarial e bandas de rock, de maneira que novos insights possibilitem esses grupos musicais explorarem novas estratégias ou redirecionarem seus esforços de atuação. Nesse sentido, pode-se concluir que VBR pode auxiliar 
empreendedores musicais e artistas orientados a este estilo musical não só a compreender quais recursos em seu poder podem ser aprimorados, mas também buscar outros recursos que apoiem sua estratégia de comunicação, ou mesmo ajudá-los a definir uma estratégia própria. Procurou-se abordar o rock pelo fato de ser este, em primeiro lugar, um fenômeno repleto de influências da modernidade e por ser uma forma de música popular dominante em diversas culturas. No entanto, as considerações tratadas neste ensaio podem ser aplicadas a outros estilos de música popular.

No início do século $\mathrm{XXI}$, a indústria fonográfica passou por uma acentuada desestruturação, causada em grande parte pelo desenvolvimento da tecnologia digital. As disputas legais entre a indústria e usuários sobre novos formatos digitais como o MP3 e serviços de compartilhamento trouxeram tanto receios quanto novas oportunidades. Se por um lado grandes empresas gravadoras ainda estão intimamente envolvidas com a organização de apresentações de artistas contratados, entrevistas em diferentes mídias e ações promocionais a partir de exibições em público, por outro, para artistas-empreendedores, a internet tem possibilitado a conquista de espaços próprios e atuação direta na indústria cultural, seja através de divulgação, seja a partir da utilização da própria internet como canal direto de marketing (ANÔNIMO, 2008; ELBERSE; BERGSMAN, 2008). Independentemente das possibilidades disponíveis aos artistas, é clara a necessidade de repensarem sua realidade em meio a essas mudanças sociais e tecnológicas. A concepção da banda de rock como uma organização empresarial que opta por um conjunto de recursos que lhe permite atingir seus objetivos estratégicos certamente contribui para tal tarefa.

Por fim, pode-se considerar que diferentes conjuntos de recursos aplicados a um determinado contexto são considerados mais estratégicos e capazes de gerar níveis de desempenhos superiores que outros. Essa mesma ideia pode se apresentar no contexto de bandas de rock. Investigações acerca de combinações de recursos-chave poderiam explicar o sucesso de bandas em determinados contextos culturais, além de elucidar possíveis relações entre a eficiência e sustentabilidade 
de estratégias cooperativas entre elas, de estratégias que as auxiliem a incorporar elementos de renovação sem que incorram desgaste de imagem, ou a encontrar novos elementos que lhes permitam estabelecer uma melhor comunicação com suas audiências etc. Tais iniciativas são imprescindíveis para os artistas no cenário da indústria criativa.

Este ensaio teve como motivação ampliar o debate sobre como artistas-empreendedores e pequenas e médias gravadoras podem melhor desenvolver estratégias de modo a atingir seus objetivos, sejam eles artísticos, econômicos etc. Esse raciocínio tem como principal pano de fundo um mercado concorrencial mais acessível, possível a partir dos desenvolvimentos das tecnologias e dos processos de confecção da música.

\section{Referências}

ADNER, Ron; HELFAT, Constance E. Corporate effects and dynamic managerial capabilities. Strategic Management Journal, v. 24, n. 10, p. 1011-1025, October 2003.

AREND, R. J. Revisiting the logical and research considerations of competitive advantage. Strategic Management Journal, v. 24, n. 3, pp. 279-284, March 2003.

ANÔNIMO. Radiohead. Musicians. Creativity, v. 16, n. 2, p. 32, 2008.

BARNEY, J. B. Firm resources and sustained competitive advantage. Journal of Management, v. 17, n. 1, p. 99-120, March 1991.

BARNEY, J. B.; HESTERLY, W. S. Administração estratégica e vantagem competitiva. São Paulo: Pearson Prentice Hall, 2007.

BENDASSOLI, P. F.; WOOD, JR., T.; KIRSCHBAUM, C.; CUNHA, M. P. e. Indústrias Criativas: definição, limites e possibilidades. Revista de Administração de Empresas, v. 49, n. 1, p. 10-18, jan./mar. 2009.

BOWIE, H. Reason to Rock: Rock Music as Art Form. Disponível em: <http://www.reasontorock.com>. Acesso em: 10 fev. 2014. 
CAVES, R. E. Creative Industries. Cambridge: Harvard University Press, 2000.

CHAHARBAGHI, K.; LYNCH, R. Sustainable competitive advantage: towards a dynamic resource-based strategy. Management Decision, v. 37, n. 1, p. 45-50, 1999.

CLARK, P. A magic science: rock music as a recording art. Popular Music, v. 3, n.1, p. 195-213, January 1983.

CORNELISSEN, J. P. Metaphor and the dynamics of knowledge in organization theory: a case study of the organizational identity metaphor. Journal of Management Studies, v. 43, n. 4, p. 683-709, June 2006.

DAY, G. S. The capabilities of market-driven organizations. Journal of Marketing, v. 58, n. 4, p. 37-52, October, 1994.

DENSKI, S. W. Music, Musicians, and Communication: the personal voice in a common language. In: LULL, James. Popular Music and Communication. 2 ed. London: Sage Publications, 1992. p. 33-48.

DURANT, A. Rock revolution or time-no-changes: visions of change and continuity in rock music. Popular Music, v. 5, n.1, Continuity and Change, January 1985. p. 97-121.

ELBERSE, A.; BERGSMAN, J. Radiohead: music at your own price. Teaching Case. Harvard Business School, May 2008. p.508-110.

FAHY, J. The resource-based view of the firm: some stumbling blocks on the road to understanding sustainable competitive advantage. Journal of European Industrial Training, v. 24, n. 2/3/4, p. 94 -104, February, 2000.

FAHY, J.; SMITHEE, A. Strategic marketing and resource based view of the firm. Academy of Marketing Science Review, v. 10, n. 1, p. 1-21, 1999.

FORNÄS, J. The future of rock: discourses that struggle to define a genre. Popular Music, v. 14, n. 1, p. 111-125, January 1995. 
FRITH, S. Sound Effects: youth, leisure, and the politics of rock ' $n$ ' roll. New York: Pantheon Books, 1981a.

. The industrialization of popular music. In: LULL, James (ed). Popular Music and Communication. 2nd ed. London: Sage Publications, 1992, p. 49-74.

. The magic that can set you free: the ideology of folk and the myth of the rock community. Folk or Popular? Distinctions, Influences, Continuities. Popular Music, v. 1, n.1. p. 159-168, January 1981 b.

FURRER, Olivier; THOMAS, Howard; GOUSSEVSKAIA, Anna. The structure and evolution of the strategic management field: A content analysis of 26 years of strategic management research. International Journal of Management Reviews, v. 10, n. 1, pp. 1-23, March 2008.

GAVETTI, Giovanni; LEVINTHAL, Daniel A. The Strategy Field from the Perspective of Management Science: divergent strands and possible integration. Management Science, v. 50, n. 10, pp. 1309-1318, October 2004.

GIBSON, O. Fãs agora fazem investimentos financeiros em bandas de rock. O Estado de São Paulo, São Paulo, 8 set. 2008. Negócios, p. B12.

GROSSBERG, L. Another boring day in paradise: rock and roll and the empowerment of everyday life. Popular Music, v. 4, n. 1, Performers and Audiences, p. 225-258, June 1984.

HALL, R. The strategic analysis of intangible resources. Strategic Management Journal, v. 13, n.2, p. 136-139, February 1992.

HAMM, C. The fourth audience. Folk or popular? Distinctions, influences, continuities, Popular Music, v. 1, p. 123-141, January 1981.

HEADLAM, D. Blues transformations in the Music of Cream. In: COVACH, J.; BOONE, G. M (eds). Understanding Rock: essays in musical analysis. New York: Oxford University Press, 1997, p. 59-92. 
HELFAT, C. E.; RAUBITSCHEK, R. S. Product sequencing: co-evolution of knowledge, capabilities and products. Strategic Management Journal, v. 21, n. 10-11, p. 961-979, 2000.

HITT, M.; IRELAND, R. D.; HOSKISSON, R. E. Strategic Management: competitiveness and globalization. 3.ed. Cincinnati: SouthWestern College, 1998. 628p

JULIEN, O. The diverting of musical technology by rock musicians: the example of double-tracking. Popular Music, v. 18, n. 3, p. 357-365, October 1999.

LONGFELLOW, M. Pink Floyd - The Making of "The Dark Side of the Moon". Eagle Rock Entertainment, 92 minutos, 2003.

LULL, J. Popular Music and Communication: an introduction. In: LULL, James (ed). Popular Music and Communication. 2nd ed. London: Sage Publications, 1992.

MILLER, D.; SHAMSIE, J. The resource-based view of the firm in two environments: the Hollywood film studios from 1936 to 1965. Academy of Management Journal, v. 39, n. 3, p. 519-541, June 1996.

MOLL, J. Foo Fighters Back and Forth. Spitfire Pictures, 135 minutos, 2011.

MORGAN, G. Imagens da Organização. São Paulo: Atlas, 1996.

NAKANO, D. A produção independente e a desverticalização da cadeia produtiva da música. Gestão e Produção, São Carlos, v. 17, n. 3, p. 627-638, jul.- set. 2010.

NIETO, M.; PEREZ, W. A firm's assets as a foundation for strategy. The Learning Organization, v. 9, n. 1, p. 19-28, 2002.

NIKETTA, R. Rock musicians in Germany and ideas for their promotion. Popular Music, v. 17, n. 3, p. 311-325, October 1998.

NOWOTNY, H.; SCOTT, P.; GIBBONS, M. Re-thinking science knowledge and the public in an age of uncertainty. Oxford: Polity Press, 2001. 
PENROSE, E. T. The Theory of the Growth of the Firm. New York: Wiley, 1959.

PEREIRA, M. S.; S. H. A. C. FORTE. Visão baseada em recursos nas instituições de ensino superior de Fortaleza. Revista de Administração Contemporânea, v. 12, n. 1, p. 107-129, Jan./Fev./Mar. 2008.

PERELMAN, C.; OLBRECHTS-TYTECA, L. Tratado da Argumentação: a nova retórica. São Paulo: Martins Fontes, 1996.

PETERSON, R. A. Why 1955? Explaining the advent of rock music. Popular Music, v. 9, n. 1, p. 97-116, Jan 1990.

PINDER, C. C.; MOORE, L. F. The resurrection of taxonomy to aid the development of middle range theories of organizational behavior. Administrative Science Quarterly, v. 24, n. 1, p. 99-118, 1979.

PRAHALAD, C.; HAMEL, G. The core competence of the corporation. Harvard Business Review, v. 68, n. 3, p. 79-91, May/June 1990.

SMITH, D. C. The importance and challenges of being interesting. Journal of the Academy of Marketing Science, v. 31, n. 3, p. 319-322, 2003.

TEECE, David J.; PISANO, Gary; SHUEN, Amy. Dynamic Capabilities and Strategic Management. Strategic Management Journal, v. 18, n. 7, p. 509-533, August 1997.

TEKMAN, H. G.; HORTAÇSU, N. Aspects of stylistic knowledge: what are different styles like and why do we listen to them. Psychology of Music, v. 30, n. 1 , p. 28-47, April 2002a.

TEKMAN, H. G.; HORTAÇSU, N. Music and social identity: stylistic identification as a response to musical style. International Journal of Psychology, v. 37, n. 5, p. 277-285, Sep 2002b.

THOMPSON, J.; COLE, M. Strategic competency - the learning challenge. Journal of Workplace Learning, v. 9, n. 5, p. 153-192, 1997. 
TINKER, T. Metaphor or reification: are radical humanists really libertarian anarchists? Journal of Management Studies, v. 23, n. 4, p. 363-384, July 1986.

TOFFLER, A. The Third Wave. New York: Bantam Books, 1990.

VERGARA, S. C. Métodos de Pesquisa em Administração. São Paulo: Atlas, 2005.

VERGARA, S. C.; CARPILOVSKY, M. P. A Metáfora da organização como sistema criativo. Revista de Administração Pública, v. 32, n. 3, p.77-98, 1998.

WICKE, P.; DEVESON, R. Rock Music: a musical-aesthetic study. Popular Music, v. 2, número especial, p. 219-243, 1982.

WINTER, Sidney G. Understanding Dynamic Capabilities. Strategic Management Journal, v. 24, n. 10, p. 991-995, October 2003.

Artigo recebido em: 5/10/2014

Aprovado em: 12/12/2014 